Dialectologia 23 (2019), 61-85.

ISSN: 2013-2247

Received 13 October 2017.

Accepted 19 January 2018.

\title{
LINGUISTIC AND NON-LINGUISTIC FACTORS AFFECTING INTELLIGIBILITY ACROSS CLOSELY RELATED VARIETIES IN PENTECOST ISLAND, VANUATU
}

\author{
Charlotte GoosKENS ${ }^{1}$ \& Cindy SCHNEIDER ${ }^{2}$ \\ University of Groningen, The Netherlands ${ }^{1}$ / University of New England, Australia ${ }^{2 *}$ \\ c.s.gooskens@rug.nl / cschnei3@une.edu.au
}

Abstract

Mutual intelligibility between speakers of four related language varieties spoken in the northern half of the island of Pentecost in Vanuatu (Raga, Suru Kavian, Suru Rabwanga and Suru Mwerani) is investigated. Raga is a separate language spoken in the northernmost part of Pentecost and is intelligible to varying degrees to speakers of the other three varieties. The other three varieties are considered dialects of the same language, Apma. However, intelligibility between the dialects is asymmetric. Although Suru Kavian speakers claim to understand Suru Rabwanga and Suru Mwerani without difficulty, speakers of the latter two varieties maintain that they have significant problems understanding Suru Kavian. These claims are supported by the results.

To explain the intelligibility results they were correlated with quantitative measures of linguistic (phonetic and lexical distances) and non-linguistic (geographical distances and a measure of exposure) factors that may play a role in mutual intelligibility.

\section{Keywords}

Intelligibility, linguistic distances, exposure, closely related languages, Vanuatu

* Charlotte Gooskens - Center for Language and Cognition, Postbus 716, 9700 AS Groningen, The Netherlands. / Cindy Schneider - Linguistics, Room 176, Arts Building E11, University of New England Armidale, NSW 2351, Australia. 
FACTORES LINGÜÍSTICOS Y NO LINGÜÍSTICOS QUE AFECTAN A LA INTELIGIBILIDAD A TRAVÉS DE VARIEDADES ESTRECHAMENTE RELACIONADAS EN LA ISLA DE PENTECOSTÉS, VANUATU

\section{Resumen}

En este artículo se investiga la mutua inteligibilidad entre hablantes de cuatro variedades lingüísticas relacionadas que se hablan en la mitad norte de la isla de Pentecostés en Vanuatu (Raga, Suru Kavian, Suru Rabwanga y Suru Mwerani). Raga es una lengua separada que se habla en la parte más septentrional de Pentecostés y es inteligible en diversos grados a los hablantes de las otras tres variedades. Las otras tres variedades se consideran dialectos de la misma lengua, Apma. Sin embargo, la inteligibilidad entre los dialectos es asimétrica. Aunque los hablantes del Suru Kavian afirman entender el Suru Rabwanga y el Suru Mwerani sin dificultad, los hablantes de las últimas dos variedades sostienen que tienen problemas significativos para entender el Suru Kavian. Estas afirmaciones son confirmadas por los resultados.

Para explicar los resultados de inteligibilidad, se correlacionaron con medidas cuantitativas de factores lingüísticos (distancias fonéticas y léxicas) y no lingüísticas (distancias geográficas y una medida de exposición) que pueden tener un papel en lo que concierne a la mutua inteligibilidad.

\section{Palabras clave}

Inteligibilidad, distancias lingüísticas, exposición, lenguas cercanas relacionadas, Vanuatu

\section{Introduction}

There are between 6,000 and 7,000 languages in the world, but by some estimates, this figure may be halved by the end of this century (May 2006: 257); some even predict losses of up to 90\% (Krauss 1992: 7; Newman 2003: 1; Nettle \& Romaine 2000: 6-7). The issue of mutual intelligibility is an important consideration in the study of dialect and language shift: how well can groups of speakers understand one another, and how does this impact upon language usage? Intelligibility studies have been carried out in various parts of the world, for example in Africa (Yanga \& Kamwangamalu 1998) and China (Tang \& Van Heuven 2008). A recent large study focuses on the Germanic, Romance, and Slavic language families of Europe (Gooskens et al. 2018). In linguistically rich areas of the world like Melanesia, mutual intelligibility is potentially an important contributor to language and dialect shift, but this issue has thus far been ignored. 


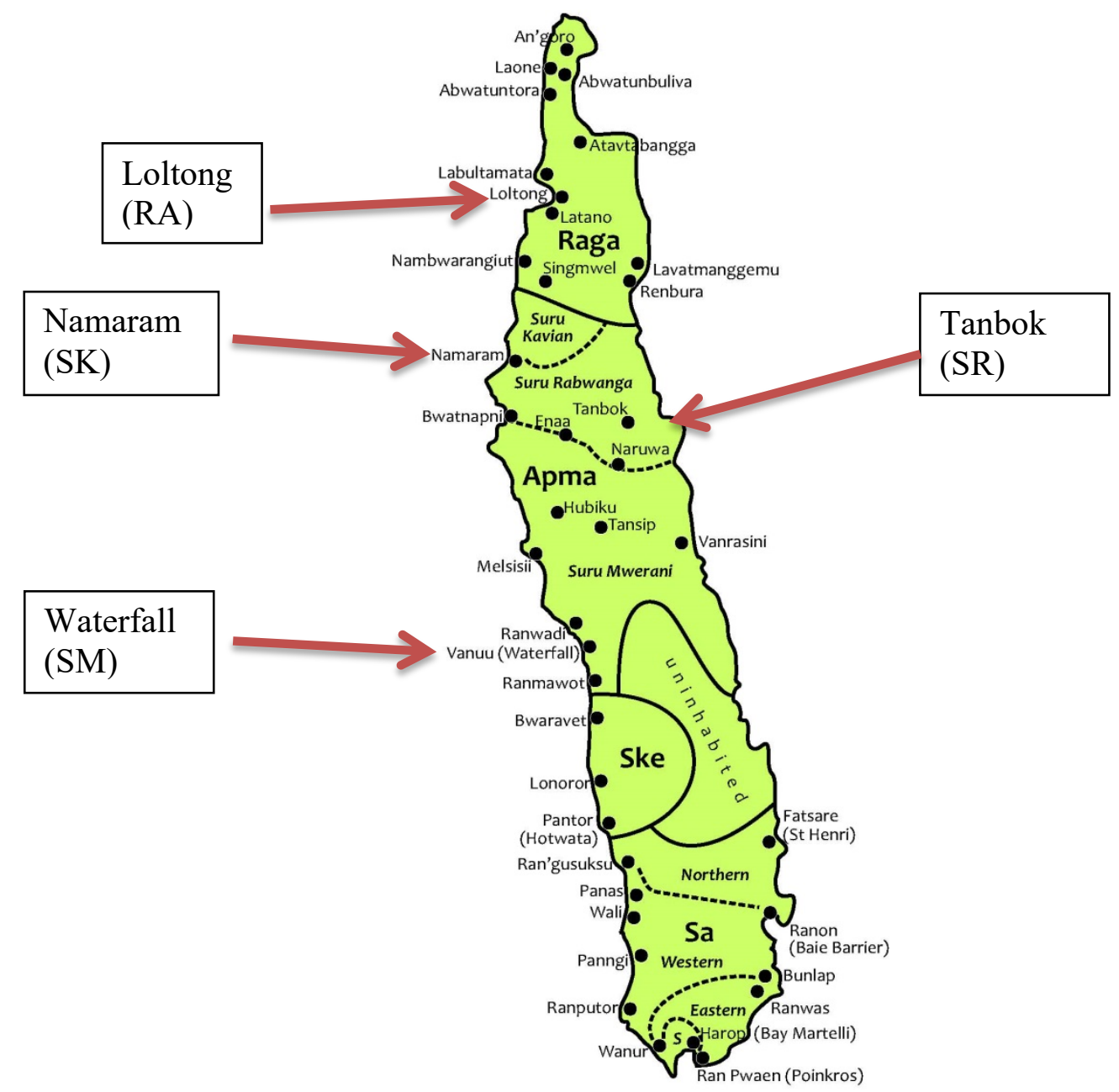

Figure 1. Present-day languages of Pentecost Island (source: personal communication, Andrew Gray, 1 September 2015). Purported language boundaries are drawn in solid lines; purported dialect boundaries are drawn in dotted lines.

In this paper we report on the result of research on the intelligibility between the Raga and Apma languages of Pentecost Island, Vanuatu (see Figure 1). The degree of difference between Raga and Apma is large enough for them to be considered separate languages and they are only mutually intelligible to a limited extent. They have different vocabularies and phonological systems. According to Tryon (1976: 106) the cognacy rate is $52 \%$. Within Apma, there are three dialects: Suru Kavian, Suru Rabwanga, and Suru Mwerani. While Suru Rabwanga and Suru Mwerani have minimal differences with each other and share $99 \%$ cognacy, Suru Kavian is more distinctive. Its cognacy with Suru Rabwanga and Suru Mwerani is only $90 \%$, which is relatively low in comparison to Suru Rabwanga and Suru Mwerani's shared cognacy (Gray 2012: 14). With only 250 speakers, 
Suru Kavian is also small in comparison to Suru Rabwanga and Suru Mwerani (which together have about 7,750 speakers), and it is also small relative to Raga at its northern border (8,000 speakers). While Suru Mwerani, Suru Rabwanga and Raga are extremely vital, Suru Kavian is on the verge of dialect shift, and is representative of the type of shift that is happening in other small communities in the Pacific. Suru Kavian speakers are renowned for their propensity to abandon their variety when conversing with nonspeakers. The reason for this, as reported by speakers and non-speakers of Suru Kavian alike, is that while Suru Kavian speakers can understand other varieties, speakers of other varieties cannot understand Suru Kavian (Schneider 2017). Intelligibility between Suru Kavian and other varieties would therefore appear to be asymmetrical. A greater understanding of the factors that influence intelligibility will contribute to a better comprehension of the mechanisms behind language and dialect shift not just in this small community, but also in others like it.

One important factor in explaining intelligibility is linguistic difference. If a language is linguistically similar to a speaker's native language, he or she is likely to be better able to understand it than if it is linguistically less similar. Differences can be found at all linguistic levels. Previous research (Gooskens \& Van Heuven, 2019; Gooskens 2007) has shown that lexical and phonetic distances correlate especially highly with intelligibility. A second factor is the amount of contact the speakers have with each other since this determines the extent to which they are exposed to each other's varieties. The amount of exposure to a language variety is likely to influence how well a speaker can understand this language variety. Through exposure the speaker will get used to the sounds of the variety and their correspondences to the sounds in his or her own variety. He or she is also likely to learn some of the vocabulary.

The authors conducted mutual intelligibility testing across Raga, Suru Kavian, Suru Rabwanga, and Suru Mwerani. In the present paper we discuss possible factors affecting intelligibility, both linguistic and non-linguistic. It is important to understand such factors because intelligibility (or a lack thereof) plays a role in language vitality. A variety that is well understood is likely to be used more frequently; its status is therefore reinforced and language maintenance is fostered. On the other hand, if a variety is poorly understood then it is less likely to be used, thus leading to shift. 
In Gooskens \& Schneider (2016) we presented results of intelligibility measurements between the Raga and Apma varieties. In the present paper we will have a closer look at the intelligibility results. We are interested in explaining the differences in intelligibility between the various groups of participants by quantifying (a) the linguistic distances between the language varieties, and (b) the amount of exposure the participants have had to the varieties.

We will quantify lexical and phonetic distances by applying dialectometric measurements developed in a European context for measuring mutual intelligibility and dialect distance to the multilingual, minority-language context of Pentecost. Exposure will be quantified in two ways. First, we will measure geographic distances between the places where the test varieties are spoken and the villages of the participants. It can be expected that participants have more exposure to varieties that are spoken nearby than to those spoken further away. Second, we will calculate the percentages of non-cognates (historically unrelated words) that the test participants can understand. The assumption is that a participant will only be able to understand a non-cognate if he or she has had some exposure to the language variety, so participants with little exposure to the test variety are expected to translate few non-cognates correctly while participants with a lot of previous exposure to the test language will get high scores in the intelligibility test.

We will first give a short summary of how we tested intelligibility between the language varieties in our investigation (Section 2). Next we will show how we quantified linguistic distances and exposure (Section 3), and finally we will look at the relationship between intelligibility and the explaining factors (Section 4). Section 5 provides a discussion and conclusion.

\section{Mutual intelligibility between language varieties of northern Pentecost}

In a traditionally oral society like Pentecost, written tasks would be culturally inappropriate and would limit participation to a non-representative sample of the population. Therefore we developed two oral word intelligibility tests: a translation task and a picture pointing task. The results of the two tests correlated highly $(r=.99, p<.01$; 
see Gooskens \& Schneider 2016), which shows that the picture task and the translation task both test intelligibility in the same manner. We also have evidence that the two word intelligibility tests are well able to capture real-life intelligibility. We correlated the intelligibility results with the scores of intelligibility as perceived by the participants (see Section 2.1) and got significant correlations $(r=.86, p<.01$ for the translation task and $r=.84, p<.01$ for the picture task). Since the two word intelligibility tests correlated so highly, we only present the results of the translation task here. In this section we give a short overview of the translation task. We only provide the information for the analysis presented in this paper. For detailed information about the method and results of our study in its entirety we refer the reader to Gooskens \& Schneider (2016).

\subsection{Method}

To test intelligibility between varieties spoken on Pentecost, we made a random selection of 40 nouns and 40 verbs from a list of 247 words compiled by Andrew Gray (personal communication, 30 $0^{\text {th }}$ May 2012). This list is itself based on one that Tryon (1976) had composed with the aim of producing a classification of the approximately 105 languages of the New Hebrides, the colonial name for the island group in the South Pacific Ocean that is now known as Vanuatu. We decided to include both nouns and verbs to get a representative sample of the languages. Furthermore, we expected differences in intelligibility between the two word classes. We anticipated a higher Raga comprehension score for Suru Mwerani verbs than for Suru Kavian verbs. This is because, similar to Raga $\left\{m^{w} a\right\}$, Suru Mwerani normally encliticizes $\left\{m^{w} e=\right\}$ to imperfective verb roots. The same morpheme occurs much less frequently in Suru Kavian (only before verb roots beginning either with vowels or with $/ r /$ ). However, $\left\{\mathrm{m}^{\mathrm{w}} \mathrm{e}=\right\}$ in Suru Mwerani can take various forms, whereas Raga $\left\{\mathrm{m}^{\mathrm{w}} \mathrm{a}=\right\}$ is invariant. Furthermore, both Suru Kavian and Suru Mwerani use $\{$ te $\}$ to encode perfectivity, which is largely unrecognizable by Raga speakers who use $\{n u\}$ to convey the same concept.

We made recordings of female speakers of the varieties included in the investigation (Raga, Suru Kavian and Suru Mwerani). The speakers read aloud the lists of 
40 nouns and 40 verbs in their native variety. On the basis of these recordings we prepared the listening material.

For the intelligibility experiment we used a semi-crossed design. The participants each listened to the recordings of 15 nouns and 15 verbs in the three Pentecost varieties and never listened to the same word twice. Each word was followed by a pause of five seconds, during which the participant gave a spoken translation of the word into Bislama, the official language of Vanuatu that fulfils the role of a lingua franca. The second author noted down for each word whether the participant translated it correctly. After each pause, a beep signaled the next word.

Before the intelligibility experiment, the participants were asked a number of questions about their personal background (gender, age, education, current village of residence, native dialect, mother's and father's native dialect). We were also interested in how the participants themselves perceived the intelligibility of the test languages, so we asked them whether they understood each of the test languages ('yes', 'no' or 'a little').

We tested participants from the territories of our speakers. They were native speakers of the language of the village where the testing was conducted. Our test villages were Loltong (for Raga speakers), Namaram and surrounds (for Suru Kavian speakers) and Waterfall (for Suru Mwerani speakers). In addition, we tested Suru Rabwanga speakers. Suru Rabwanga was not included as a test language because it is $99 \%$ cognate with with Suru Mwerani and we wanted the testing session to be short. However, we still wanted to test to see how well Suru Rabwanga speakers in the village of Tanbok could understand their neighbors. Tanbok is closer to Suru Kavian and Raga territory than to Waterfall, so even though Suru Rabwanga and Suru Mwerani dialects are very similar, Suru Rabwanga speakers may understand their neighbors better than Suru Mwerani speakers because that have been exposed to their language varieties more often. 


\begin{tabular}{|l|l|l|l|}
\hline \multicolumn{1}{|c|}{ Participant group } & \multicolumn{1}{|c|}{ N } & Mean age & \multicolumn{1}{c|}{$\begin{array}{c}\text { Mean years at } \\
\text { school }\end{array}$} \\
\hline Loltong & 22 & 42.2 & 8.1 \\
(Raga, RA) & $(15 \mathrm{M}, 7 \mathrm{~F})$ & $(18-69)$ & $(3-14)$ \\
\hline Namaram & 26 & 31.8 & 6.9 \\
(Suru Kavian, SK) & $(17 \mathrm{M}, 9 \mathrm{~F})$ & $(16-64)$ & $(0-14)$ \\
\hline Tanbok & 31 & 33.3 & 4.9 \\
(Suru Rabwanga, SR) & $(14 \mathrm{M}, 17 \mathrm{~F})$ & $(16-59)$ & $(0-12)$ \\
\hline Waterfall & 32 & 37.6 & 7.8 \\
(Suru Mwerani, SM) & $(20 \mathrm{M}, 12 \mathrm{~F})$ & $(18-68)$ & $(3-15)$ \\
\hline
\end{tabular}

Table 1. Total Number of participants per village, broken down by males $(M)$ and females $(F)$; mean age; and mean number of years of education. Between brackets the ranges are given.

In Table 1 we summarize the characteristics of the 111 participants included in the analysis of this paper. ${ }^{1}$ The Tanbok and Namaram participants were a bit younger (mean ages of 31.8 and 33.3 years) than the participants from Loltong (42.2) and Waterfall (37.6). The Tanbok participants had had little schooling (mean of 4.9 years) compared to the other participant groups (6.9 to 8.1 years). In Tanbok there were also more female than male participants, while in the other villages it was the other way around.

\subsection{Intelligibility results}

We calculated the mean percentage of correct translations per language combination. In the left column of Table 2 , the first language in each language combination denotes the linguistic background of the participants and the second denotes the variety being tested. For example, 'RA-SK' refers to Raga participants being tested for their comprehension of Suru Kavian. In total there are nine language combinations. We calculated the mean percentages of translations of all words per language combination, as well as of the nouns and the verbs separately.

\footnotetext{
${ }^{1}$ We tested both adults and children, but in this paper we are concerned only with the testing of adults. The results of the children are presented in Schneider \& Gooskens (2017).
} 


\begin{tabular}{|l|c|c|c|}
\hline & $\begin{array}{c}\text { Translations } \\
\text { all } 80 \text { words }\end{array}$ & $\begin{array}{c}\text { Translations of } \\
\text { 40 nouns }\end{array}$ & $\begin{array}{c}\text { Translations of } \\
\text { 40 verbs }\end{array}$ \\
\hline RA-SK & 20.7 & 22.3 & 19.1 \\
SK-RA & 81.5 & 81.5 & 81.5 \\
RA-SM & 26.7 & 33.6 & 19.4 \\
SM-RA & 20.1 & 23.1 & 17.0 \\
SK-SM & 94.0 & 93.7 & 94.6 \\
SM-SK & 46.7 & 48.8 & 44.5 \\
SR-RA & 42.5 & 38.1 & 47.2 \\
SR-SK & 57.2 & 59.4 & 54.0 \\
SR-SM & 93.2 & 96.3 & 89.5 \\
\hline Mean & 53.6 & 55.2 & 51.9 \\
\hline
\end{tabular}

Table 2. The mean percentages correct word translations per language combination for all words as well as the results for the nouns and the verbs separately. For abbreviations see Table 1.

The differences between percentage of correct translations of nouns and verbs is generally small (a mean of 55.2 for the nouns and 51.9 for the verbs across all language combinations). The largest difference is found for Raga participants listening to Suru Mwerani words (33.6 for the nouns and 19.4 for the verbs). This difference is significant at the .05 level ( $n=21, t=2.279$ ). This confirms our expectations (see $\S 2.1$ ). We also anticipated a higher Raga comprehension score for Suru Mwerani verbs than for Suru Kavian verbs. However, the score for Suru Mwerani verbs is only slightly higher than for Suru Kavian verbs (19.4 versus 19.1). It is possible that Raga speakers were just as confused by the variants of $\{m w e=\}$ in Suru Mwerani as they were by the lack of any form at all in Suru Kavian. Furthermore, both Suru Kavian and Suru Mwerani use $\{$ te $\}$ to encode perfectivity, which is largely unrecognizable by Raga speakers who use nu\} to convey the same concept.

Looking now at the results for the individual language combinations we see that there are large differences. The lowest score is found for Suru Mwerani participants listening to Raga words (20.1\%) which can be expected since these two language varieties are classified as different languages and the geographic distance between the villages is the largest. Raga participants understood more Suru Mwerani words (26.7\%), but the difference is not significant. Suru Rabwanga participants understood a reasonable number of Raga words (42.5\%), probably due to the close position of the village of Tanbok to the Raga area. Raga participants had difficulties with Suru Kavian (20.7\%). The scores are lower than for the other Apma dialect, Suru Mwerani (26.7\%), even though Suru 
Kavian is geographically closer than Suru Mwerani. This can probably be explained by the fact that Suru Mwerani is linguistically very similar to Suru Rabwanga which is spoken in the border area of the Raga area. Suru Kavian participants on the other hand have high scores for Raga (81.5\%) even though the two varieties are categorized as different languages. Within the Apma language we note that Suru Kavian participants had high scores for Suru Mwerani (94.0\%), while both Suru Mwerani and Suru Rabwanga participants had much lower scores when listening to Suru Kavian (46.7\% and $57.2 \%)$. This asymmetry can probably be explained by the fact that Suru Kavian speakers have a high degree of exposure to other languages and dialects due to the small number of Suru Kavian speakers (Schneider \& Gooskens 2017). It has been noted before that Suru Mwerani and Suru Rabwanga speakers have difficulties understanding Suru Kavian and even sometimes consider it a different language. Suru Rabwanga and Suru Mwerani, finally, are very closely cognate with only minimal dialectal differences; Suru Rabwanga participants understand Suru Mwerani well (93.2\%). We will look at factors that may explain the intelligibility results in greater detail in the following sections.

\section{Quantifying explaining factors}

In this section we explain how we quantified two kinds of factors (linguistic distances and exposure) that may play a role in explaining the mutual intelligibility of the language varieties in our investigation.

\subsection{Linguistic distances}

\subsubsection{Lexical distances}

Following Seguy (1973) we defined lexical distance between two languages as the percentage of non-cognates in each of the languages compared to the other languages in the investigation. An example of a non-cognate pair in our material is the word for 'forest', which is utevono in Raga and leewakina in Suru Kavian. These two words are 
historically unrelated. Since there were a total of 80 RA-SK word pairs, and of these, 37 were non-cognate, the lexical distance for RA-SK is $37 / 80$ or $46.3 \%$. We calculated distances for nouns and verbs separately as well as the means across all 80 words.

\subsubsection{Phonetic distances}

We based the phonetic distance calculations on broad phonetic transcriptions of the words in the intelligibility experiments. The transcriptions were made by the second author on the basis of the recordings of the words. Phonetic distance is computed for the aligned cognate word pairs in each pair of languages. The degree of dissimilarity between cognates is computed by the Levenshtein algorithm, which computes the smallest number of string edit operations needed to convert the phonetic string in language $A$ to the string in B. Possible string operations are deletions, insertions and substitutions of symbols. We illustrate this algorithm by comparing the Raga word [ $\mathrm{m}^{\mathrm{w}}$ alua] with the Suru Kavian cognate [lia't] '(he/she) vomits' in Table 3.

\begin{tabular}{lllllll}
\hline Alignments & 1 & 2 & 3 & 4 & 5 & 6 \\
\hline Raga & $\mathrm{m}^{\mathrm{w}}$ & $\mathrm{a}$ & $\mathrm{I}$ & $\mathrm{u}$ & $\mathrm{a}$ & \\
$\begin{array}{l}\text { Suru Kavian } \\
\text { Number of operations }\end{array}$ & 1 & 1 & $\mathrm{i}$ & 1 & 1 & 1 \\
\hline
\end{tabular}

Table 3. Illustration of the Levenshtein algorithm (see explanation in text).

In the first two slots [ $\left.\mathrm{m}^{\mathrm{w}}\right]$ and [a] are deleted, in the fourth slot [u] is replaced by [i], in the fifth slot [a] is replaced by [a'] and in the sixth slot [t] is inserted. The total number of operations is then divided by the length of the alignment (number of alignment slots) to yield a length-normalized Levenshtein distance. The word [ $\mathrm{m}^{\mathrm{w}} \mathrm{alua}$ ] can be mapped to [lia't] in many different ways, but the Levenshtein distance always gives the cost of the cheapest mapping. The minimum cost is based on an alignment in which a vowel matches with a vowel and a consonant matches with a consonant. As there are five operations and the alignment has six slots, the distance is calculated as $(5 / 6) \times 100=83.3 \%$. The overall phonetic distance from language $A$ to language $B$ is the arithmetic mean of the 
normalized distances for all cognate word pairs. The measure is symmetrical between word pairs by definition. For more background and explanation about the Levenshtein algorithm, see Nerbonne \& Heeringa (2010).

\subsection{Exposure}

We did not ask the participants questions about their exposure to the test languages, but still we think that it is possible to quantify the amount of exposure. We present two kinds of exposure measures below: geographical distance and percentages of incorrectly translated non-cognates.

\subsubsection{Geographic distances}

In previous research geographical distances have been found to correlate highly with linguistic distances (Spruit et al. 2009; Nerbonne \& Kleiweg 2007). We also expect geographical distances to correlate significantly with intelligibility. Participants are likely to be more exposed to varieties spoken in geographically close places than to more remote varieties. So, for example, we predict that Suru Rabwanga speakers are more exposed to Raga and Suru Kavian than Suru Mwerani speakers are because their village, Tanbok, is close to the Raga and Suru Kavian territories and they will therefore understand more Raga and Suru Kavian words than Suru Mwerani speakers will. We measured geographic distance in two ways. The first measure is straight line distances in kilometers ('as the crow flies'), measured by inserting GPS coordinates for each village in Google maps. However, previous research has shown that travel distances may be a better reflection of linguistic distances than straight line geographical distances (Inoue 2008; Gooskens 2005). The second measure therefore calculates the distance in kilometers by road by Google Maps. However, there are very few roads on Pentecost. The inhabitants usually walk from one village to the other on small paths that are not indicated on Google maps. Some of the paths lead across the mountains so the kilometer count given by Google maps does not necessarily reflect the effort of going from one village to another very well. A better measurement might be the time it takes to walk 
from one village to the other, but we do not have access to such information. Straight line distances and travel distances correlate highly and the correlation with intelligibility is slightly higher for travel distances than for straight line distances. Therefore in our analysis we only include the travel distances as a representation of geographical distances. We expect geographical distances to correlated negatively with intelligibility scores. If participants live far from the place where the test language is spoken, they will have little exposure to the language and therefore low intelligibility scores while they will translate more words correctly if the test language is spoken in a place close to their own village.

\subsubsection{Percentages of incorrectly translated non-cognates.}

If participants have hardly been exposed to a language before they are unlikely to be able to understand non-cognates since they cannot understand them on the basis of correspondences in their own language. Therefore a way to quantify exposure is to calculate the mean percentages of non-cognates understood for each language combination. Many incorrectly translated non-cognates are likely to reflect little exposure while participants can be expected to be able to translate many non-cognates correctly if they are often exposed to the language. We expect a negative correlation with intelligibility. ${ }^{2}$

\subsection{Results of linguistic and exposure measurements}

In Table 4 we present the results of the lexical and phonetic distance measures per overall language combination, as well as for nouns and verbs separately. We also present the geographic distances and percentages of incorrectly translated non-cognates. The linguistic and geographical distances are symmetric. So, for example, the lexical distance between Raga and Suru Kavian is the same as the distance from Suru Kavian to Raga

\footnotetext{
${ }^{2}$ We calculated the percentage of wrongly translated non-cognates rather than the percentage of correctly translated non-cognates in order to get a negative correlation like for the geographical distances. So for both exposure measurements, high numbers reflect little exposure.
} 
(46.3\%). We did not test the intelligibility of Suru Rabwanga, but we tested how well Suru Rabwanga participants could understand the other languages. Therefore only one linguistic measurement is presented. The percentages of incorrectly translated noncognates differ per language combination. So, for example, Raga participants translated $76.6 \%$ of Suru Kavian non-cognates incorrectly while Suru Kavian participants only translated $24.7 \%$ of the non-cognates incorrectly.

\begin{tabular}{|l|r|r|r|r|r|r|r|r|}
\hline & \multicolumn{10}{|c|}{ Explaining factors } \\
\hline & \multicolumn{1}{|l|}{$\begin{array}{l}\text { Lex. } \\
\text { dist. }\end{array}$} & $\begin{array}{l}\text { Lex. } \\
\text { dist. } \\
\text { nouns }\end{array}$ & $\begin{array}{l}\text { Lex. } \\
\text { Dist. } \\
\text { verbs }\end{array}$ & $\begin{array}{l}\text { Phon. } \\
\text { dist. }\end{array}$ & $\begin{array}{l}\text { Phon. } \\
\text { dist. } \\
\text { nouns }\end{array}$ & $\begin{array}{l}\text { Phon. } \\
\text { list. } \\
\text { verbs }\end{array}$ & $\begin{array}{l}\text { Geo. } \\
\text { dist. } \\
\text { (km.) }\end{array}$ & $\begin{array}{l}\text { \% incorr. } \\
\text { non-cogn. }\end{array}$ \\
\hline RA-SK & 46.3 & 47.5 & 45.0 & 57.0 & 53.9 & 60.0 & 29.7 & 76.6 \\
SK-RA & 46.3 & 47.5 & 45.0 & 57.0 & 53.9 & 60.0 & 29.7 & 24.7 \\
RA-SM & 45.0 & 45.0 & 45.0 & 55.0 & 57.0 & 52.9 & 53.6 & 70.7 \\
SM-RA & 45.0 & 45.0 & 45.0 & 55.0 & 57.0 & 52.9 & 53.6 & 79.0 \\
SK-SM & 12.5 & 15.0 & 10.0 & 26.6 & 22.9 & 30.3 & 30.5 & 5.0 \\
SM-SK & 12.5 & 15.0 & 10.0 & 26.6 & 22.9 & 30.3 & 30.5 & 82.2 \\
SR-RA & 45.0 & 45.0 & 45.0 & 54.9 & 56.5 & 53.3 & 24.8 & 58.0 \\
SR-SK & 11.3 & 12.5 & 10.0 & 24.4 & 21.7 & 27.1 & 11.9 & 56.3 \\
SR-SM & .0 & 2.5 & .0 & 4.1 & .7 & 7.6 & 32.4 & - \\
\hline Mean & 29.3 & 30.3 & 28.3 & 40.1 & 38.5 & 41.6 & 33.0 & 56.5 \\
\hline
\end{tabular}

Table 4. Measurements of lexical and phonetic distances (overall and separately for nouns and verbs) and exposure measurements (geographical distances and percentages of incorrect translations of noncognates).

The linguistic distances between Raga and Suru Kavian are generally largest, while the distances between Suru Rabwanga and Suru Mwerani are smallest. Note that Suru Kavian is not linguistically closer to Raga than Suru Mwerani and Suru Rabwanga. This means that the superiority of Suru Kavian participants in the intelligibility tests does not seem to be caused by linguistic factors but rather to the fact that they are more familiar with the test languages due to more exposure. Suru Kavian participants translated the largest percentage of non-cognates correctly while Suru Mwerani participants have the lowest scores. We will go into further detail about the results of the linguistic and exposure measurements when discussing the correlations between intelligibility and the various factors in Section 4. At this point we would like to make a few notes.

First, all the differences between nouns and verbs are non-significant, both for the lexical distances and for the phonetic distances. Since the intelligibility differences between nouns and verbs were also small and only significant for Raga participants tested 
in Suru Mwerani, we will only include overall distances (means of nouns and verbs) when looking at the relationship between results of the translation task and the explaining factors.

Secondly, note that because of the way the factors were quantified most of them do not show asymmetry. For example, the linguistic distances from Raga to Suru Kavian are the same as the distances from Suru Kavian to Raga. Only the percentages of incorrect translations of non-cognates are asymmetric, since the different groups of participants may have different exposure to the test languages. Especially when Suru Kavian participants are involved, there is a large asymmetry. No percentage is reported for Suru Rabwanga participants listening to Suru Mwerani because there were no non-cognates for this language combination.

Finally, we would like to mention that the lexical distances that we found are similar to those established by Gray (2012: 14). This is not surprising since we based our selection on Gray's wordlist of 247 words. He found 1\% non-cognates between Suru Mwerani and Suru Rabwanga, and 10\% between Suru Kavian and the other two Apma varieties. Raga is considered a different language and has $40 \%$ non-cognates with Apma varieties (Gray 2012: 14). This means that our random selection of 80 words represents the larger dataset well.

\section{Relationship between intelligibility and (non-)linguistic factors}

To get an impression of the relationship between intelligibility and (non-) linguistic factors we first correlated the mean intelligibility scores (percentages of correctly translated words) per language combination (Table 2) with the linguistic distances (lexical, phonetic) and exposure measurements (geographic distances and percentages of incorrect translations of non-cognates, see Table 4). The results are presented in Table 5. 


\begin{tabular}{|l|l|l|l|l|}
\hline & \multicolumn{3}{|c|}{ Explaining factors } \\
& $\begin{array}{l}\text { Lexical } \\
\text { dist. }\end{array}$ & $\begin{array}{l}\text { Phon. } \\
\text { dist. }\end{array}$ & $\begin{array}{l}\text { Exposure: } \\
\text { Geo. dist. }\end{array}$ & $\begin{array}{l}\text { Exposure: } \\
\text { \% incorr. transl. non- } \\
\text { cogn. }\end{array}$ \\
\hline Intelligibility & -.640 & -.653 & -.420 & $-.921^{* *}$ \\
\hline Lexical distances & & $.985^{* *}$ & .435 & .248 \\
\hline Phonetic distances & & & .382 & .238 \\
\hline Exposure: geo. dist. & & & & .309 \\
\hline
\end{tabular}

Table 5. Correlations between intelligibility scores (percentages of correct translations of all words), linguistic distances (lexical and phonetic distances) and exposure (geographical distances and percentages of incorrect translations of non-cognates). ${ }^{* *}=$ significant at .01 level.

The correlations between the intelligibility scores (the percentage of correctly translated words) and the linguistic distances are not significant. The lexical and the phonetic distances have a high correlation (.985).

Large geographical distances are likely to reflect little exposure and therefore the larger the distances the fewer words the participants are likely to be able to translate correctly (negative correlation). The amount of exposure as expressed by geographical distance does not correlate significantly with intelligibility. As discussed in Section 3.2, it is possible that our way of measuring the geographical distances is not optimal for reflecting the amount of contact between speakers from the four villages.

Exposure measured as the percentages of incorrectly translated non-cognates seems to be a better reflection of the lack of exposure. The correlation with the intelligibility scores is very high $(r=-.921)$ and significant at the .01 level. The correlation between the two measures of exposure, geographical distances and percentages of incorrectly translated non-cognates, is low and insignificant $(r=.309)$ which shows that the two measures reflect different things.

It may seem a problem that the non-cognates are part of both the intelligibility test and the measure of exposure. Therefore we also correlated the intelligibility scores of a subset of cognates only with the percentages of incorrectly translated non-cognates. These two subsets of words show no overlap. If the participants had no exposure to the test language then they would translate non-cognates incorrectly, but they may still be able to translate cognates correctly because of phonetic similarities to their native languages. Also when correlating percentages of incorrectly translated non-cognates with 
the subset of correctly translated cognates, we get high correlations $(r=-.897)$ which confirms that the percentage of incorrect translations of non-cognates is a useful way to quantify the amount of exposure.

To be better able to interpret the correlations in Table 5 we made scattergrams showing the relationship between intelligibility and the four explaining factors (Figure 2). In general, there is a clear link between linguistic distances and intelligibility, large distances corresponding to low intelligibility and small distances to high intelligibility. Suru Kavian participants form an exception: they translate words better than would be expected from linguistic distances. For example, $46.3 \%$ of the Raga test words are unrelated to the corresponding Suru Kavian words, but still the Suru Kavian participants translate $81.5 \%$ of the words correctly.

Exposure measured by geographic distances between the villages of the participants also show a clear trend for most language combinations. However, Suru Kavian participants understand more than would be expected from the distances that these participants must travel to get to the other villages. They translate almost all Suru Mwerani and Raga words correctly (94.0\% and $81.5 \%)$ even though the geographical distances to the villages of the speakers of these languages is just as large as for other language combinations where intelligibility is much lower (for example Raga and Suru Mwerani participants tested in Suru Kavian). As for the scattergram showing the relationship between intelligibility and exposure expressed by the number of noncognates that are incorrectly translated, Suru Kavian is no longer an outlier. Suru Kavian participants have more exposure to the test languages than the other groups of participants. Suru Rabwanga speakers listening to Suru Mwerani are also an outlier in the graph showing geographical distances. The villages (Tanbok and Waterfall) are far apart but the language varieties are still linguistically very similar. This language combination is missing in the percentage of incorrectly translated non-cognates graph because there are no SR-SM non-cognates. 

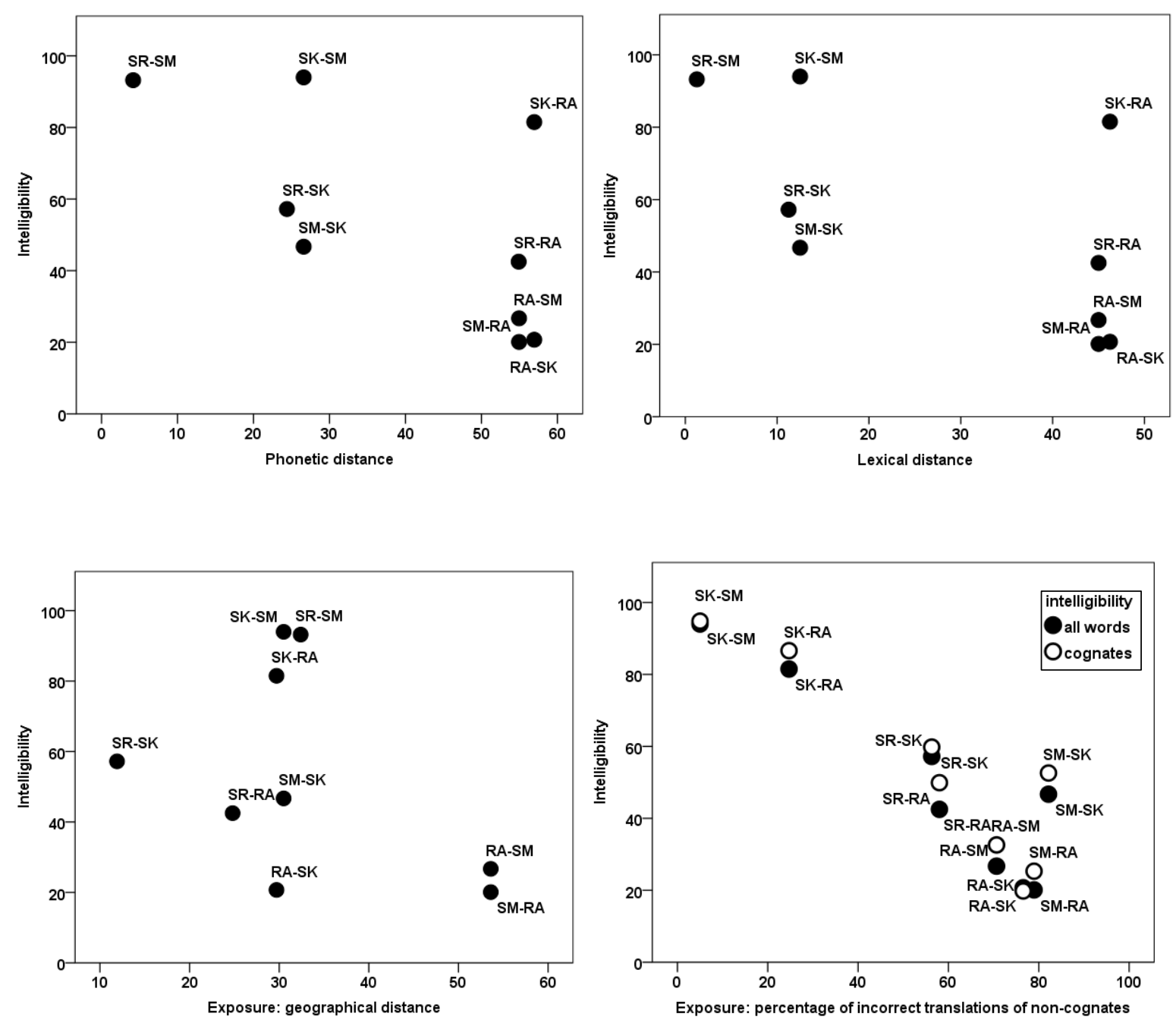

Figure 2. Scattergrams showing the relationships between intelligibility (percentage of correct translations) and the four explaining factors (lexical distance, phonetic distance, geographical distance, percentage of incorrect translations of non-cognates). Exposures as measured by percentage of incorrect translations of non-cognates is correlated with all words as well as with a subset of cognates only.

As a final step in our analysis we carried out a stepwise regression analysis with the percentages of correct translations as the dependent variable and the four explaining factors as independent variables. Only exposure (as expressed by percentages of incorrectly translated non-cognates) was included in the model. This single variable allows us to predict intelligibility with great accuracy ( $85 \%$ of the variance, $t=-5.783, p=<.001)$. An inspection of the scattergrams in Figure 2 makes clear that this does not mean that linguistic distance is not related to intelligibility. Most language combinations show a clear relationship between linguistic distances and 
intelligibility, large linguistic distances corresponding to low intelligibility scores and small distances to high scores. Suru Kavian participants form an exception. They understand Suru Mwerani and Raga better than predicted by linguistic distances, probably because they have had a lot of exposure to these varieties (see Table 4). In order to analyze the role of linguistic distances without the influence of exposure we would need to carry out a regression analysis with a data set of participants who have had no prior exposure to the test language. However, we do not have enough participants for such an analysis. As an alternative we removed the two language combinations involving Suru Kavian participants. We now get high correlations $(r=-.88$ for lexical distances and -.93 for phonetic distances) and phonetic distances are the only factor included in a stepwise regression model (86\% explained variance). Note, however, that these results are based on seven data points only. To draw stronger conclusions, we would need more data points.

Since it is not within reach to add more data points to our analysis, we decided to put our results into perspective by comparing them to results of a similar investigation in another language area, the European area. Gooskens et al. (2017) tested the mutual intelligibility of closely related Germanic, Romance and Slavic languages (in total 70 language combinations) with a word translation task involving 100 frequent nouns and correlated the results to phonetic distance. In Gooskens \& Heeringa (in preparation) the results of linguistic distance measures between the same language combinations are presented. In Figure 3 we present a scattergram of the correlation between percentages of correct translations and phonetic distances. The black circles are the nine Pentecost language combinations and the white circles are the 70 European language combinations. The phonetic distances between the Pentecost varieties generally show a larger range than the European languages and so do the intelligibility scores. However, if abstracting from the outliers involving Suru Kavian we see that the Pentecost and the European languages have similar relations between intelligibility scores and phonetic distances. The correlation between phonetic distances and the intelligibility scores involving all Pentecost and European languages is significant at the .01 level $(r=.65)$. 


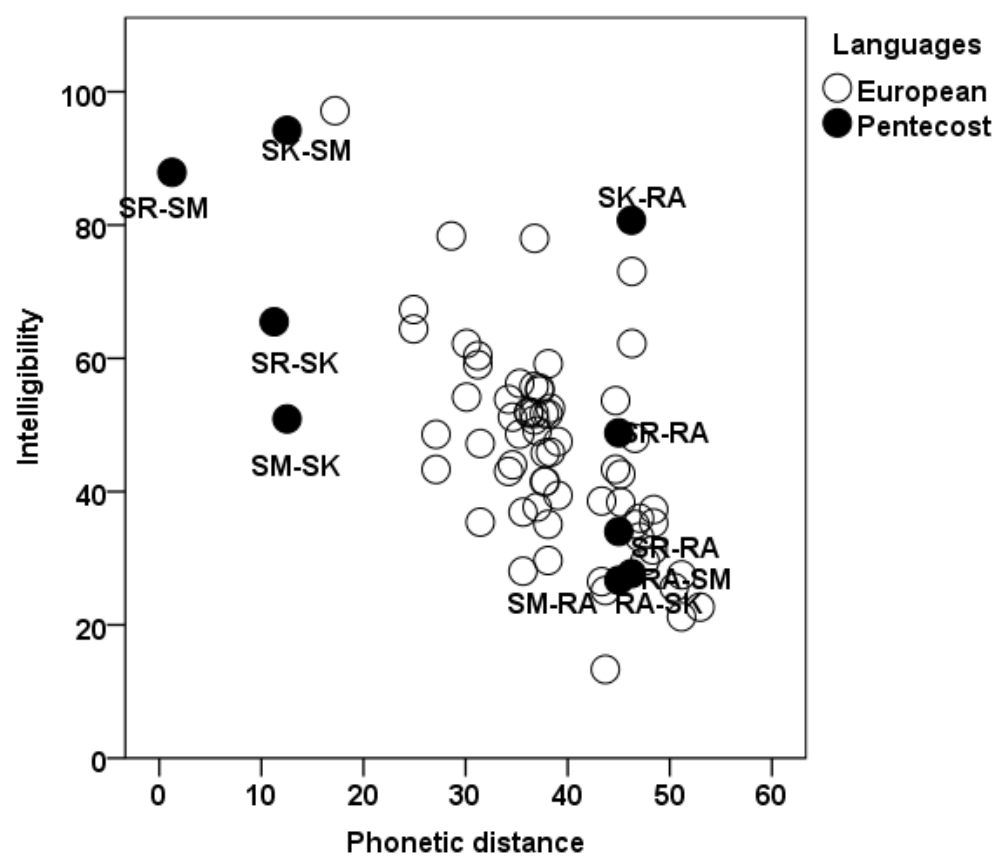

Figure 3. Scattergrams showing the relationship between intelligibility (translation task) and phonetic distances for nine Pentecost and 70 European language combinations.

\section{Discussion and conclusions}

We carried out a word translation task to establish the mutual intelligibility between related language varieties spoken in the northern half of Pentecost, one of the 84 islands of Vanuatu. The results show that the mutual intelligibility between Apma dialects (Suru Kavian, Suru Rabwanga and Suru Mwerani) is higher than intelligibility between the Apma dialects and Raga. The mutual intelligibility between Suru Kavian and all the other language varieties is asymmetric. This finding confirms reports by the inhabitants of northern Pentecost.

We quantified linguistic distances at the level of lexicon and pronunciation as well as amount of exposure that the participants in our investigation have had to the test languages. In previous intelligibility research, exposure has mostly been quantified by asking the participants to indicate how often they listen to or read the test language (e.g Delsing \& Lundin Åkesson 2005; Gooskens \& Van Heuven 2017). Since some participants could not read and write and could therefore not fill in a questionnaire and we wanted to keep the testing session as short as possible, we did not include such a questionnaire in 
our investigation. Instead we measured geographical distances because we assumed that they would reflect the amount of exposure. However, geographical distances (travel distances as calculated by Google Maps) did not correlate significantly with the intelligibility scores. A way to express geographical distances that would probably reflect exposure better would be to calculate the walking distance or the time it takes to walk between villages. Unfortunately we do not have this information. It should also be noted that the specific testing sites represent just one village in a given language area, and therefore the true distances between one language area and another may differ (substantially) from the measurements given here. E.g., Tanbok in the SR area is much closer to Hubiku (in the SM area) than it is to Waterfall (where we do the measurement to). Perhaps it would be better to measure the distance from the source village to the closest edge of the target language area.

However, based on the idea that participants are only able to translate noncognates correctly if they have had previous exposure to the test language we developed a different way to measure exposure. We correlated the percentages of incorrectly translated non-cognates with the intelligibility scores and the results show that exposure is the most important predictor of intelligibility. The amount of exposure is at least part of the explanation why the mutual intelligibility between Suru Kavian and the other language varieties is asymmetric. Suru Kavian speakers have had more exposure to the other varieties than the other way around. Suru Kavian is spoken in the center of the area and therefore the speakers have more visitors from outside the village than the other villages do. Also, Suru Kavian is spoken by only a small number of speakers. For this reason Suru Kavian speakers need to be able to understand the other languages for communicative purposes. Our analysis could be improved by adding number of speakers as an explanatory factor but, unfortunately, we did not have information about the separate number of Suru Mwerani and Suru Rabwanga speakers.

An additional non-linguistic factor that has previously been found to correlate with intelligibility is attitude. Positive attitudes can be expected to motivate participants to make a greater effort to understand a language than negative attitudes. However, the link demonstrated in experimental settings has been rather weak (e.g. Delsing \& Lundin Åkesson, 2005; Schüppert et al. 2015). It is possible that part of the explanation for the 
low intelligibility results for Suru Kavian is that the participants from the other villages have ambivalent attitudes towards this distinctive dialect, while the attitudes among Suru Kavian speakers towards other Apma and Raga varieties are more accommodating. This may be due to the simple fact that with just 250 speakers, the Suru Kavian community is very small relative to its much larger neighbors to the north and south; Suru Kavian speakers' acceptance of other varieties is a practical necessity. Furthermore, the large populations of both Raga and the other two dialects of Apma lend a certain amount of visibility to these varieties, and this may affect speaker attitudes. For future studies we suggest that attitudes be quantified by means of questionnaires, and then included as a factor in the analysis.

By correlating our results with linguistic distance measurements we showed that linguistic distances are also important predictors of intelligibility. Both lexical and phonetic distances show high correlations when removing the outliers involving Suru Kavian. Since we base these conclusions on a small number of language combinations only, we decided to put our results into perspective by comparing them to a similar analysis of European languages. This comparison showed that the relation between intelligibility scores and phonetic distances is similar in the two language areas and that the role of phonetic distances in explaining intelligibility can be generalized across language families. However, the nature of our linguistic distance measurements does not allow us to express linguistic asymmetries. The distance from language variety $A$ to variety $B$ is the same as the distance from variety $B$ to variety $A$. It is therefore not possible to draw conclusions about the role of linguistic differences in explaining the asymmetry in intelligibility between Suru Kavian and the other varieties in our investigation. In Schneider and Gooskens (2018) we had a closer look at the translations of individual Suru Kavian words by Suru Mwerani participants to gain a greater understanding of which particular linguistic phenomena form a hindrance for the participants. We conclude that an accumulation of differences makes Suru Kavian hard to understand for Suru Mwerani participants, including the existence of differences in the pronunciation of $s / t / d$ and differing vowel quality of the stressed syllable. Differences in word stress and a difference in the number of syllables also appear to have an impact on intelligibility. 
Like many small minority languages and dialects of the Pacific and elsewhere, Suru Kavian is in danger of extinction. By understanding how linguistic and non-linguistic factors operate to affect mutual intelligibility between speakers, by corollary we also gain insight into the nature of language and dialect shift in this part of North-Central Pentecost. It is only through understanding the factors behind shift that it can be stalled or reversed. Whether a variety is mutually intelligible with a neighboring variety, and to what extent, is at least one of the factors that influences the linguistic behavior of a language community - that is, whether it maintains its variety or shifts to a neighboring language. In our case, knowledge of specific linguistic and non-linguistic factors affecting intelligibility gives us some insight into why Suru Kavian speakers are shifting away from their own variety, and allows us to advise the community accordingly. The model used here can also be employed in similar contexts in the Pacific and elsewhere.

\section{References}

DELSING, Lars-Olof \& Katarina LUNDIN ÅKESSON (2005) Håller språket ihop Norden? En forskningsrapport om ungdomars förståelse av danska, svenska och norska [Does the language keep together the Nordic countries? A research report of mutual comprehension between young Danes, Swedes and Norwegians], Copenhagen: Nordiska ministerrådet.

GOOSKENS, Charlotte (2005) "Traveling time as a predictor of linguistic distance", Dialectologia et Geolinguistica, 13, 38-62.

GoOSKENS, Charlotte (2007) "The contribution of linguistic factors to the intelligibility of closely related languages", Journal of Multilingual and Multicultural Development 28 (6), 445467.

GoOSKENS, Charlotte \& Wilbert HeERINGA (in preparation) "Linguistic distances between closely related languages in Europe".

GoOSKENS, Charlotte \& Vincent J. VAN HEUVEN (2017) "Measuring cross-linguistic intelligibility in the Germanic, Romance and Slavic language groups", Speech communication 89, 25-36. 
GoOSKENS, Charlotte \& Vincent J. VAN HeUVEN (2019) “How well can intelligibility of closely related languages in Europe be predicted by linguistic and non-linguistic factors?", Linguistic Approaches to Bilingualism, https://doi.org/10.1075/lab.17084.goo.

Gooskens, Charlotte, Vincent J. van HeUven, Jelena Golubovic, Anja SCHÜPPERT, Femke SWARTE \& Stefanie VOIGT (2018) "Mutual intelligibility between closely related languages in Europe", Journal of Multilingualism, 15(2), 169-193.

GoOSKENS, Charlotte \& Cindy SCHNEIDER (2016) "Testing mutual intelligibility between closely related languages in an oral society", Language Documentation \& Conservation, 10, 278305.

GraY, Andrew (2012) The Languages of Pentecost Island, Middlesex, UK: Manples (BFoV) Publishing.

INOUE, Fumio (2008) "Geographical distance center and multivariate analysis of the standard Japanese", Dialectologia, 1, 65-81.

<http://www.publicacions.ub.edu/revistes/dialectologia1/>

KRAUSS, Michael (1992) "The world's languages in crisis", Language, 68 (1), 4-10.

MAY, Stephen (2006) "Language policy and minority rights", in Thomas Ricento (ed.), An Introduction to Language Policy: Theory and Method, Oxford: Blackwell, 255-272.

NerbonNe, John \& Wilbert HeERINGA (2010) "Measuring Dialect Differences", in Jürgen Erich Schmidt \& Peter Auer (eds.), Language and Space: Theories and Methods. Handbooks of Linguistics and Communication Science, Berlin: Mouton De Gruyter, 550-567.

NerbonNe, John \& Peter Kleiweg (2007) "Toward a Dialectological Yardstick", Journal of Quantitative Linguistics, 14 (2), 148-167.

Nettle, Daniel \& Suzanne Romaine (2000) Vanishing Voices: The Extinction of the World's Languages, Oxford: Oxford University Press.

NeWMaN, Paul (2003) "The endangered languages issue as a hopeless cause", in Mark Janse \& Sijmen Tol (eds.), Language Death and Language Maintenance, Amsterdam: John Benjamins, 1-13.

SCHNEIDER, Cindy (2017) "Ideologies, practices, and their effect on dialect vitality: a case study from Vanuatu", Journal of Multilingual and Multicultural Development, v39, n1, 60-75, DOI: 10.1080/01434632.2017.1311904.

SCHNEIDER, Cindy \& Charlotte Gooskens (2018) "A Follow-up Analysis of Listener (Mis)comprehension across Language Varieties in Pentecost, Vanuatu", Oceanic Linguistics, 57(1), 144-176. 
Dialectologia 23 (2019), 61-85.

ISSN: 2013-2247

SCHNEIDER, Cindy \& Charlotte GoOSKENS (2017) "Approaching micro-level planning from an educational perspective: A case study from Pentecost Island, Vanuatu", Journal of Multilingual and Multicultural Development, 28 (6), 530-544.

SCHÜPPERT, Anja, Nanna H. HILTON \& Charlotte Gooskens (2015) "Swedish is beautiful, Danish is ugly? Investigating the link between language attitudes and intelligibility", Linguistics, 53 (2), 375-403.

SÉGUY, Jean (1973) "La dialectométrie dans l'Atlas linguistique de la Gascogne", Revue de linguistique Romane, 37, 1-24.

SPRUIT, Marco, Wilbert HeERINGA \& John NerbonNe (2009) "Associations among linguistic levels", Lingua, 119 (11), 1624-1642.

TANG, Chaoju \& Vincent J. van Heuven (2008) "Mutual intelligibility of Chinese dialects tested functionally", in Marjo van Koppen \& Bert Botma (eds.), Linguistics in the Netherlands145156.

TRYON, Darrell T. (1976) New Hebrides languages: An internal classification. Pacific linguistics series C, no. 50, Canberra: Pacific Linguistics.

YANGA, Tshimpaka \& Nkonko KAMWANGAMALU (1998) Mutual intelligibility of the languages of the Congo Basin, Centre for Advanced Studies of African Society, Florida Hills: Vivlia. 